University of Nebraska - Lincoln

DigitalCommons@University of Nebraska - Lincoln

Copyright, Fair Use, Scholarly Communication, etc.

\title{
Achieving an Equitable Transition to Open Access for Researchers in Lower and Middle-Income Countries
}

\author{
Andrea Powell \\ Research4Life \\ Rob Johnson \\ Research Consulting \\ Rachel Herbert \\ Elsevier
}

Follow this and additional works at: https://digitalcommons.unl.edu/scholcom

Part of the Intellectual Property Law Commons, Scholarly Communication Commons, and the Scholarly Publishing Commons

Powell, Andrea; Johnson, Rob; and Herbert, Rachel, "Achieving an Equitable Transition to Open Access for Researchers in Lower and Middle-Income Countries" (2020). Copyright, Fair Use, Scholarly Communication, etc.. 168.

https://digitalcommons.unl.edu/scholcom/168

This Article is brought to you for free and open access by the Libraries at University of Nebraska-Lincoln at DigitalCommons@University of Nebraska - Lincoln. It has been accepted for inclusion in Copyright, Fair Use, Scholarly Communication, etc. by an authorized administrator of DigitalCommons@University of Nebraska Lincoln. 
Achieving an Equitable Transition to Open Access for Researchers in Lower and Middle-Income Countries

\section{Authors}

Andrea Powell, STM Outreach Director and Publisher Coordinator, Research4Life

Rob Johnson, Director, Research Consulting

Rachel Herbert, Senior Research Evaluation Manager, Elsevier 


\section{Introduction}

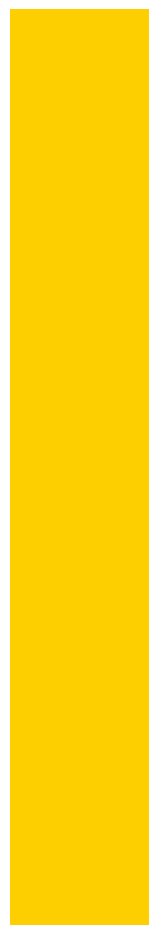

The origins of this White Paper can be traced to a discussion started in mid-2019 between a number of scholarly publishers and the Publisher Coordinator for Research4Life (a role that is supported financially by the STM Association). These interlocutors voiced concern that while the publishing and research communities in the developed world were making steady and positive progress towards universal Open Access based on a 'pay to publish' model, those same communities in the less developed lower and middle-income countries (often referred to as the "Global South") were being excluded from these discussions. Following discussions at the STM Board in the summer of 2019, an informal Task Force of publishers and other interested parties was set up to explore ways in which a transition to Open Access could be made more equitable, avoiding a situation in which the new model would simply shift the barrier from one place to another. Crucially, a research communication process based on Open Access to all outputs should not be less inclusive than the current model.

\section{Laying the Foundations: Ensuring Equality of Access to Research Information}

The Research4Life initiative has endeavored to close the knowledge gap between the industrialized North and Lower- and MiddleIncome Countries (LMICs) since it was first launched in 2002 as a partnership between the World Health Organization (WHO) and a small group of medical research publishers. The partnership now includes five United Nations (UN) Entities (WHO, Food and Agriculture Organization of the United Nations (FAO); United Nations Environment Program (UNEP); World Intellectual Property Organization (WIPO); and International Labour Organization (ILO), some 175 scholarly publishers, Yale and Cornell Universities and other parties. It provides free or very low-cost access to research publications and online resources, many of which would otherwise be locked behind a subscription paywall. As of March 2020, this access encompassed up to 23,500 research journals (including nearly 10,000 Open Access titles), 80,000 ebooks and 120 other digital resources available to over 10,000 registered institutions in eligible countries. Research4Life's eligibility criteria are based upon Gross National Income per capita, and countries are divided into Group A (free access) and Group $B$ (low cost access) on this basis. Some 125 countries are included in the program.

Access to this huge collection of information enables researchers in LMICs to stay up-to-date with the latest developments in international science and to become familiar with the standards required for publication. The need for access to, and participation in, knowledge production and dissemination is at the core of the United Nations' Sustainable Development Goals (SDGs), which are expected to shape the global agenda on economic, social and environmental development
The Task Force agreed that the first step towards addressing these challenges was to gather evidence about the progress already made towards Open Access in less advantaged regions, using the Research4Life country list (Research4Life, 2020) as a proxy, and about the obstacles preventing it from progressing more rapidly. The International Centre for the Study of Research at Elsevier offered to carry out this analysis and to make the results widely available as a basis for further discussion and analysis. This paper presents those results and captures the conclusions from a workshop held at the 2020 Researcher to Reader Conference, at which the data formed the basis for debate over how to make an Open Access publishing system more equitable.

for the next decade or so. Indeed, the agenda recognizes that access to information is not an outcome of development but a catalyst for it; ensuring barrier-free access to research through Open Access publication models or initiatives like Research4Life is a non-negotiable requirement for the attainment of the Goals.

Despite the efforts of Research4Life and similar initiatives, however, the contribution made by researchers in its eligible countries as authors, editors and peer reviewers remains low, and the number of articles authored by researchers in Research4Life countries as a percentage of the total corpus seems to have increased only very modestly over the past ten years (see 'Establishing a baseline' below). Clearly, there is a persistent inequity and imbalance, which is proving challenging to resolve, despite increased access to research knowledge. As the research communication system evolves (albeit gradually) towards universal Open 


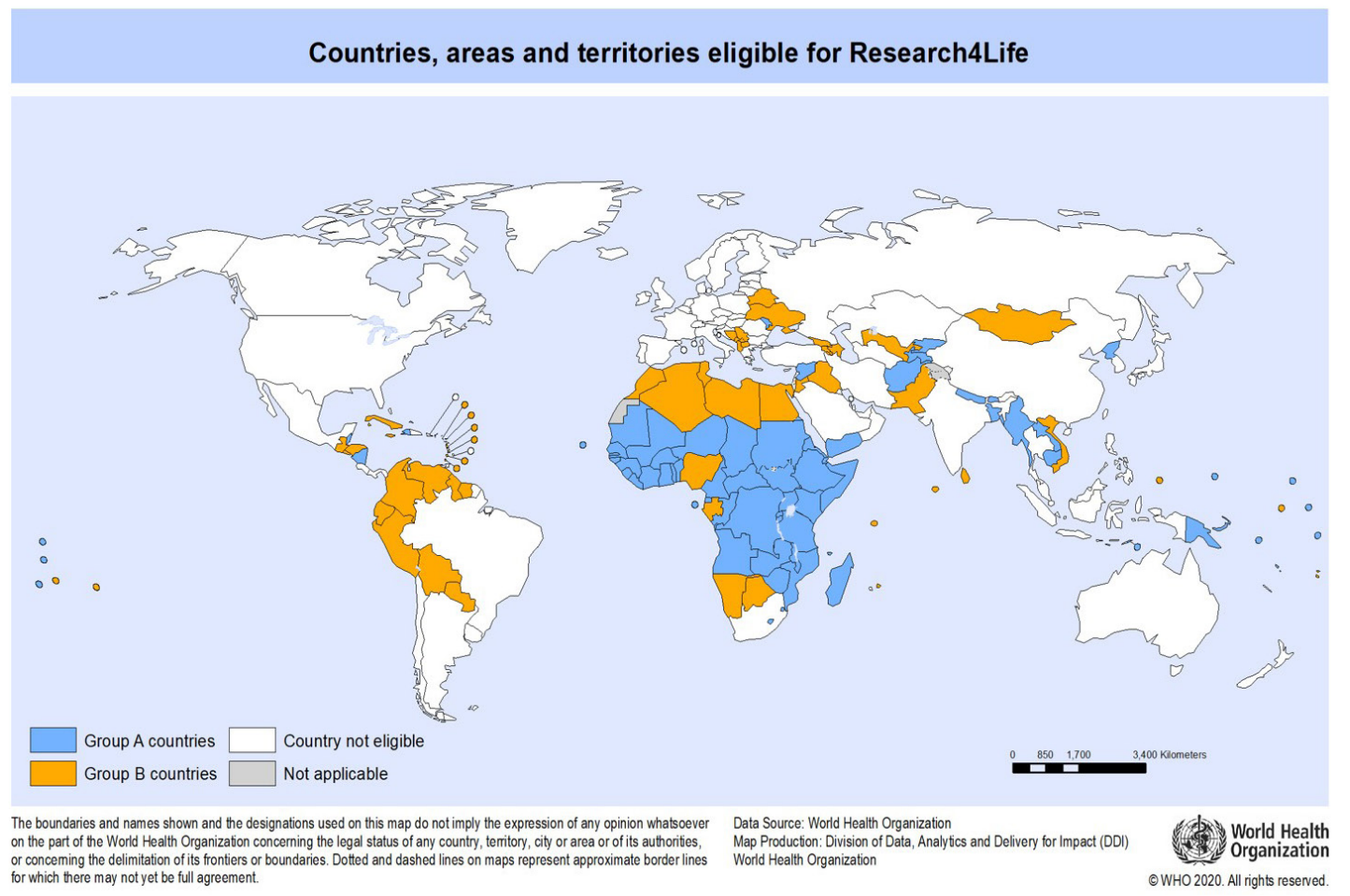

Figure 1:

World map highlighting countries eligible for the Research4Life programme

Access, there are no guarantees that this disparity will naturally disappear or even diminish, unless some positive action is taken to remove some of the obstacles inherent in current Open Access business models (see 'Leveling the Playing Field' below).

\section{Influence of the}

\section{UN's Sustainable}

\section{Development Goals}

This lack of inclusion and diversity in the research communication process should be a concern to us all, especially with so many stakeholders in the sector now aligning their own strategies and objectives with the goals and targets defined in the SDGs (Purcell, Henriksen, \& Spengler, 2019); (Warden, 2017). Delivery on these objectives will likely require a recalibration of research to balance work on new discoveries with the application of existing and new knowledge for innovations to (among other things) eliminate extreme poverty, protect human rights, reduce child mortality, promote gender equality, improve crop productivity and halt the spread of HIV/AIDS, malaria, COVID-19 and other diseases.

The outputs from this research must be communicated effectively to have any impact, and appropriate systems of quality control and validation must be applied to ensure they are reliable and trustworthy. Again, this effort must be inclusive and involve researchers, practitioners, policy makers and communicators from LMICs who can create and nurture local capabilities, peer networks and communications infrastructure. 


\section{Open Access Business Models}

There are many definitions of Open Access, and different business models are applied to support the costs of publication. This figure, taken from the 2018 STM Report, (Johnson, Watkinson, \& Mabe, 2018) usefully illustrates the range of models currently employed across the scholarly and professional publishing sector:

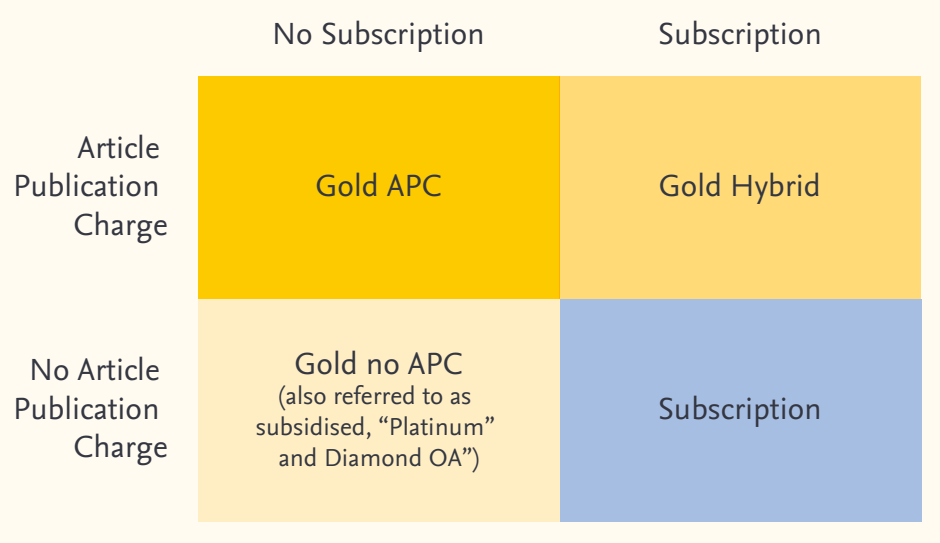

Overview of Open Access business models

Without a doubt, the lack of access to funding and budgets for paying Article Publication Charges (APCs) is a major obstacle for many researchers in LMICs wishing to publish Open Access research. Although most international publishers offer fee waivers to authors in Research4Life countries (and others), lack of awareness of such policies and a lack of consistency in their application can, cause confusion and hinder take-up of Open Access publishing options (Research4Life, 2013). Further, as Open Access scales in volume, it is unclear whether the waivers that publishers offer could be sustained at the same levels. Evidence cited in this report (see Figure 4 in 'Uptake of Open Access publishing' below) indicates that subscription journals remain the most common choice for many authors in LMICs. There is emerging evidence elsewhere that those authors can often end up paying APCs even when they are eligible for a discount or total waiver (Nobes \& Harris, 2019).

As more journals make the transition to an Open Access business model, will a new obstacle - an inability to publish rather than to read - simply exacerbate this lack of representation from LMICs in the literature? A system that requires payment from the author, or the author's institution, is likely to be unsustainable for impoverished regions or disciplines, and future inclusion may require a combination of commercial and noncommercial platforms and publications with the support of both private and public sector players.

\section{Leveling the Playing \\ Field for Authors}

In order to identify ways to improve the inclusivity and equity of the research communication ecosystem, first we should characterize and quantify the size of the challenge and identify the main obstacles facing researchers in LMICs when it comes to making their work openly and freely accessible alongside that of their peers in more advantaged countries.

There is no simple (or single) reason for the current imbalance; lack of funding is at the top of the list, but many countries also have poorly developed national research programs and a lack of cohesion between research and policy-making, as well as underdeveloped publishing sectors. Others are emerging from decades of conflict and have lost skills and experience to other countries or regions through displacement or economic necessity.

\section{How can we Collaborate to Support the Transition to Open Access in LMICs?}

At the Researcher to Reader Conference in February 2020, a workshop involving stakeholders from across the community (including from some Research4Life countries) examined this challenge and identified a number of practical steps which publishers, among others, can take to avoid putting obstacles in the path toward universal Open Access. The outcomes and recommendations from this workshop, including data and findings used to ground and prompt the discussion, are presented in this report, along with some thoughts on how Research4Life can leverage its status as a global non-profit partnership to support researchers in their quest to communicate the outputs of their research. 


\section{Establishing a Baseline}

In considering the transition to Open Access among LMICs, it is important that we understand the current levels of uptake of this form of scholarly publication. To do so, we looked at publications indexed in Scopus where there was at least one author affiliated with a Research4Life country. In 2018, we counted 154 thousand publications (Figure 2), representing 5.5\% of the world's total output in the same year - an increase from $3.1 \%$ in 2009. Compared to ten years prior, there has been growth in terms of absolute output, which rose by $10.5 \%$ per year (Compound Annual Growth Rate, 2009-18). This growth compares very favorably to the global research output growth (3.6\% CAGR, 2009-18), though the base for the growth is significantly lower. Despite the barriers around access to published research then, authors from Research4Life countries are demonstrating growth in volume of output.

\section{Growth in Scholarly Output from Research4Life Countries}

Notably, the growth in scholarly output is increasing - with stronger growth in more recent years. The highest year over year growth was between 2017 and 2018, when it reached $16 \%$. And the growth in the last five years is stronger than that of the full ten: $11.9 \%$ CAGR 2014-18.

What's driving this growth? We considered a few drivers, including increases in the number of active researchers, the average publication rate per researcher, and growth in the topics in which these researchers are publishing. In the main, the publication rate - the average number of publications per author - has remained steady across the ten-year period. And there was a little more growth in the social sciences than in other disciplines, but that remains a small share of the total output and so is not a key driver. However, the overall unique number of researchers affiliated

\section{Measuring growth}

In this report, we tend to report growth using the Compound Annual Growth Rate (CAGR). This is the mean annual growth rate over a period of more than one year. It measures the change between the first and final year, accounting for growth and any volatility in growth. In contrast, year on year growth rates are simple measure of the growth between one year and the following.

with Research4Life countries has been growing, as indicated by the total count of authors. In fact, the number of authors affiliated with these countries more than doubled between 2014 and 2018 and so it appears to be this that is driving the increase in volume of scholarly publications.

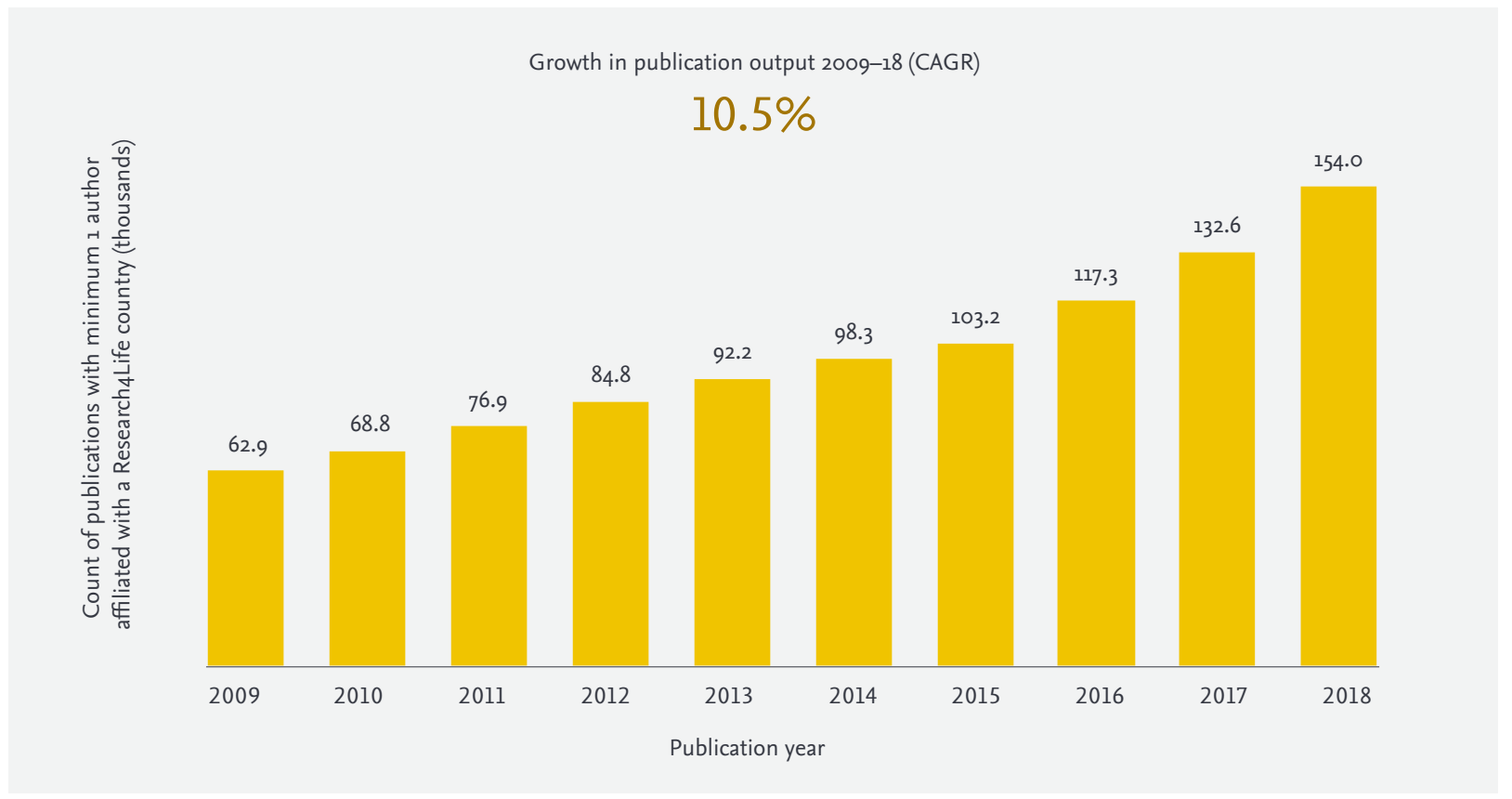

Figure 2: Count of publications with at least one author from a Research4Life country. Source: Scopus. Full counting on articles, reviews, conference papers and short surveys; deduplicated so that publications with more than one author from a Research4Life country are counted only once. 


\section{Coverage of Research4Life publications}

To measure the participation of authors from Research4Life countries, we used Scopus.com, which indexes more than 22,800 journals. This gives very broad coverage of scholarly publications from around the world (almost 80 million publications), but a notable limitation of the results in this report is that some journals of local importance may not be covered. For example, among the criteria for indexation, Scopus requires that publication titles and abstracts are written in English (the full publication may be written in any language); this is likely to exclude some local language journals and low- and middleincome countries may be disproportionately affected. The existing coverage is, nevertheless, understood to demonstrate authors from Research4Life countries' contribution to the international scholarly literature.

\section{Every Country has a Story}

As with almost any large cohort, there are variations within the data at a more granular level, and we can identify differing stories within the Research4Life eligible countries when we consider scholarly output volume and growth (Figure 3).

Many of the Research4Life countries published a relatively low volume of publications in 2018: just under 100 of the countries published fewer than 1,000 publications. However, three countries alone accounted for just over $30 \%$ of the total output namely: Egypt, Pakistan and Ukraine. Venezuela is the only country to demonstrate negative growth in output over the ten years, but political and economic upheaval in the country's recent history is known to have resulted in research capacity loss and departure of researchers (Bifano, 2014).

Iraq demonstrates the highest growth in publications between 2009 and 2018 , largely driven by an increased capacity for research following the end of trade sanctions in 2003 (Wired, 2013). And Vietnam has made the development of education, training, science and technology a national priority since at least 2012 (Thanh Tien, 2016) - so we can suppose that this effort may be behind that country's growing research output.

\section{Uptake of Open Access Publishing}

Data from Scopus and Unpaywall demonstrates that Open Access publishing is growing in popularity

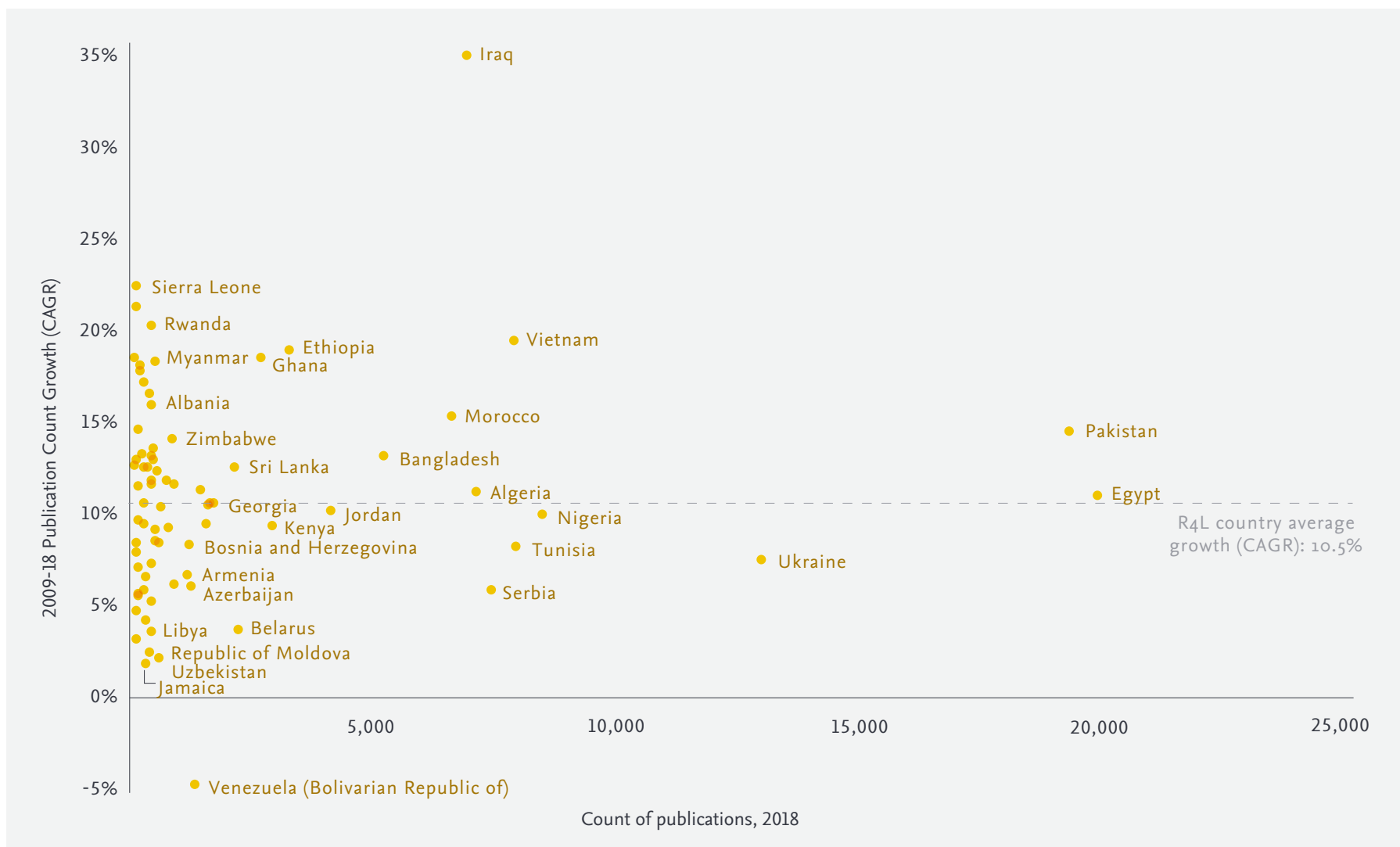

Figure 3: Count and growth of publications with at least one author from each Research4Life country. Chart displays countries with at least 100 publications in 2018. Source: Scopus. Full counting on articles, reviews, conference papers and short surveys; deduplicated so that publications with more than one author from a Research4Life country are counted only once. 
among authors from Research4Life countries, but the majority of publications are still published under a subscription model ( $75 \%$ in 2018) either in subscription-only journals or in those that offer a choice of subscription or Open Access (Figure 4).

Of those publications published in Open Access, the Gold APC model — in which authors would typically be asked to pay an article publishing charge (APC) to enable immediate open access upon publishing - is the most popular (16\% in 2018). Subsidized Open Access plays a part too - these are journals for which the costs of publication are subsidized by another body, perhaps an institution or society, associated with the journal, meaning there is no APC for the author. The least popular model (though growing the fastest from a very low base) is hybrid uptake - that is, Gold APC Open Access in otherwise subscription-based journals.

These findings jibe well with those seen across a wider research community both in terms of the shares and the growth trends: the subscription model is still the preferred option for publishing authors, with the Gold APC model the growing favorite among the Open Access options that we studied. However, the share of hybrid uptake is a little lower among Research4Life authors.

In the Researcher to Reader conference workshop, the group discussed the potential reasons behind these results. It's likely that there are a number of reasons, among them a lack of funding, perhaps a lack of understanding of the availability of APC waivers, and inconsistent information and policies on waivers among publishers, making it difficult to understand the options. We also know that the level of motivation to publish research under an Open Access business model is often low among authors - and not just those in Research4Life countries (Shih, 2017). And, of course, not all of the research publications that we captured from Research4Life authors would have been eligible for waiver of the APC, for example, if waivers are conditional on the corresponding author being from a Research4Life country.

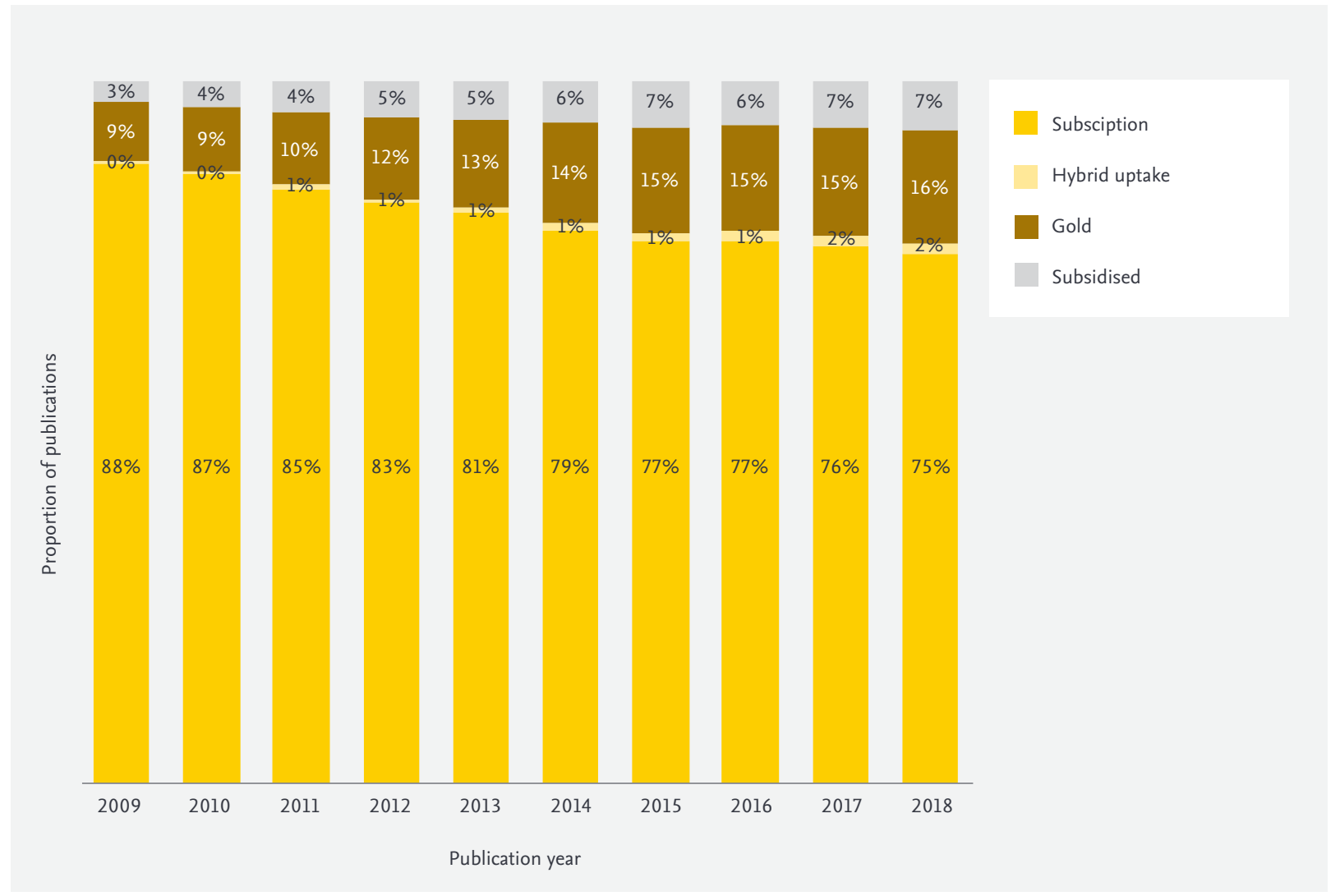

Figure 4: Share of publications with minimum one author from each Research4Life country by Open Access model. Source: Scopus and Unpaywall data for publication-level Open Access model. Full counting on articles, reviews, conference papers and short surveys; deduplicated so that publications with more than one author from a Research4Life country are counted only once. 


\section{A Preference for 'International' Journals}

Another way to consider how authors from Research4Life countries are sharing their research is to look at the journals in which they publish. More specifically, the question we considered as whether the journals in which Research4Life authors publish tend to be populated with publications from other Research4Life authors. For each journal in which a Research4Life author published, we identified the share of publications with at least one author who is affiliated with a Research4Life country across the journal as a whole. Using $60 \%$ as a minimum threshold, we then looked at what proportion of all publications with a Research4Life author appeared in this subset of journals (Figure 5)
The results show us that there is no particular preference among our cohort for publishing in the same journals where other Research4Life authors publish, and that in fact, the preference is moving increasingly in the opposite direction. The threshold of $60 \%$ is somewhat arbitrary, but the story doesn't change if we shift that either up or down a little: consistently, the preference for publishing in journals where Research4Life authors predominate is low and declining over time.

\section{Alternative Routes to Openness}

Posting preprints offers another route to openness. Preprint servers are popping up regularly now, but use of them is somewhat limited to certain fields of research, so we chose to look at bioRxiv, the preprint server for biology. We found that, of the 10,615 preprints posted to bioRxiv during 2017 which we captured, 226 had at least one author affiliated with a Research4Life country. That represents $2.1 \%$ of the year's total output (Figure 6).

As an imperfect but useful comparison, 4.1\% of journal articles in Scopus's biology subject area have at least one author affiliated with a Research4Life country (Figure 6). So we might conclude that Research4Life authors are underrepresented in this form of open scholarly communication.

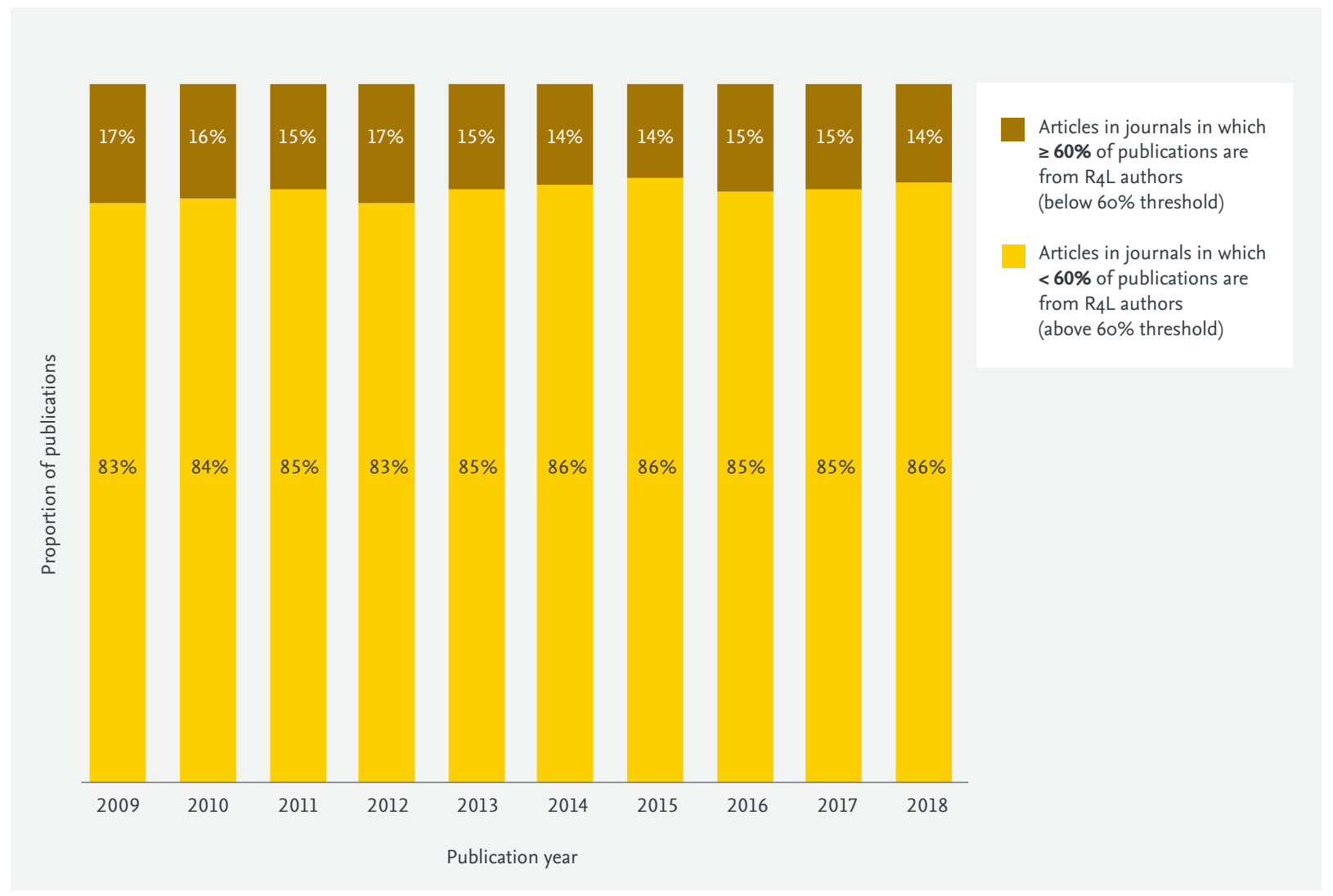

Figure 5: Share of publications in journals with more and less than $60 \%$ of publications from R4L authors. Source: Scopus. Full counting on articles, reviews, conference papers and short surveys; deduplicated so that publications with more than one author from a Research4Life country are counted only once. 


\section{Practical ways to Support} Researchers in LMICs

The findings from this analysis demonstrate that there is a limited but gradually growing appetite for Open Access publishing among authors from LMICs, a strong and growing preference for international journals, and (perhaps) relatively little participation in preprinting. An equitable transition towards Open Access for LMIC-based researchers needs support from all within the research community. Many stakeholder groups are working hard to develop sustainable models that will achieve the goal of $100 \%$ Open Access, recognizing that there is unlikely to be a "one size fits all" solution, given widely variable funding levels, geography, incentives and discipline. Another limitation is that each type of stakeholder, from research funder to individual researcher, can only influence a certain aspect of the research and dissemination cycle.

\section{At the Researcher to Reader} conference workshop, a number of practical options were identified as ways of providing support to researchers in LMICs for achieving their Open Access publishing ambitions, with a focus on actions that can be taken by publishers unilaterally, or preferably, collectively. This is not an exhaustive list, but the following actions could help to ensure that researchers in less wellfunded regions can achieve greater levels of exposure and equality among their published peers.

\section{Greater Consistency and Transparency around APC Waivers}

One relatively simple solution is to make publisher policies on APC waivers more consistent and more transparent. Even though this business model may turn out to be an interim step on the road to universal Open Access, it is likely to persist

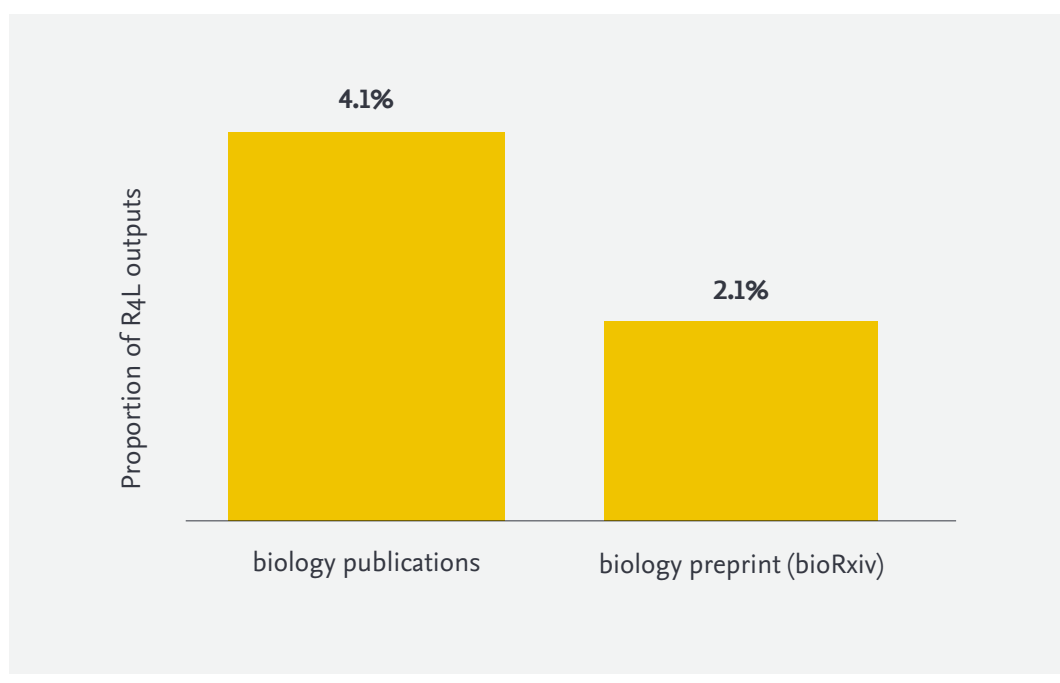

Figure 6: Share of publications in Scopus's biology subject category published in 2017 compared with the share of bioRxiv preprints posted in 2017 with at least one author affiliated to a Research4Life country. Source: bioRxiv and Scopus. Full counting on articles, reviews, conference papers and short surveys; deduplicated so that publications with more than one author from a Research4Life country are counted only once.

for several years to come and may unwittingly end up preventing much important research from reaching its intended audience.

In the short term, authors would benefit from waiver information being more accessible. Policies should be made available more clearly and conspicuously on journal and publisher websites.

For example, could all publishers charging APCs agree to waive such charges automatically for anyone from a Research4Life registered institution? If differentiation between Group A and Group B countries is required, could the former automatically receive a 100\% waiver and the latter a $75 \%$ waiver?

Monitor Pilot Projects to Model a

Transition to Open Access for

\section{LMIC institutions}

Many publishers have announced large "read and publish" deals with major academic library consortia, smoothing the transition to Open
Access by combining the costs of reading with the costs of publishing in their journals in the expectation that publishing costs will gradually replace reading costs. In instances where the purchasing consortium is already spending a considerable amount to purchase subscriptions to journals, this transformation can be modeled and tested. However, in cases where access to journals is provided at very low cost or free through initiatives like Research4Life, there are no existing budgets to transition, so this model needs rethinking. Pilot studies are exploring how such an approach could be adapted for library consortia in LMICs (Information Power, 2020).

Greater Involvement of Researchers from LMICs in Editorial Boards and Peer Review systems

A September 2018 report (Publons, 2018) by Publons and Clarivate Analytics paints a similar picture of participation in the peer review process. Since journal editors 
tend to be based in developed and industrialized countries, requests to review often naturally exclude authors and potential reviewers from countries outside of their usual network. Fewer invitations to review means fewer opportunities to see the latest research trends, to learn what journals are looking for, to build professional networks and to develop critical skills.

Publishers could examine their journal editorial boards and their peer reviewer databases to ensure that they are diverse and reflect areas of future growth, not just the status quo. They may have to accept that researchers from LMICs may face a steeper learning curve than other reviewers and invest in building their capacity as contributors as well as readers.

Better Capacity Building Resources aimed at Authors, Reviewers and Editors from LMICS

Many publishers and development organizations like INASP provide training programs and materials aimed at researchers wanting to publish their work in recognized and peer-reviewed journals. It makes sense for the publishing community to collaborate on these efforts, rather than providing journal- or publisher- specific training collateral; these skills are pre-competitive and transferable. Running such programs on a large scale and at regular intervals requires financial support from donors and other benefactors. Here again, joint ventures like Research4Life and non-profits like INASP can help to provide channels to the end-user community in lowerand middle-income countries, but they will continue to depend on support, both financial and in-kind, from participating publishers and other donors.

Encourage and Showcase Collaboration between the Industrialized Regions and $\mathrm{LMICS}$

Institutions might consider existing networks that could be leveraged to ease the path to more inclusive research collaborations, challenging existing preconceptions and drawing attention to the "filter bubbles" we all subconsciously inhabit. Conference-planning committees should proactively seek speakers and panelists from around the globe as part of an expanding diversity agenda, particularly now that virtual conferencing is likely to become the "new normal" in a post-COVID-19 world. Furthermore, all researchers should be mindful of ensuring that the work they reference is global, where appropriate.

And publishers can share data from their own submissions and publications regarding activity among Research4Life authors, especially around Open Access uptake, to promote understanding about the participation of authors from LMICs in the research communication process.
Support for the Publication of Research relevant to the Sustainable Development Goals (SDG)

A 2019 report (Clarivate Analytics, 2019) from Clarivate Analytics confirms a redirection of research towards the UN's shared goals, revealing evidence from the Web of Science that, increasingly, research programs are being influenced directly by specific SDG targets and goals, not just reflecting general global trends. Publishers would do well to study the SDG agenda to identify topics that are likely to increase in priority and research funding over the coming decade and to consider what titles and platforms might be appropriate for optimal dissemination of the outputs of this research.

\section{Leverage Research4Life's status as a Global Non-profit Partnership}

Research4Life can support efforts made by its publisher partners in many ways, building on its relationships with stakeholders in all sectors of the research communication ecosystem. It can, for example, support publishers by creating an area on its website that provides an index to publishers' APC waiver policies addressing the problem described above. Researchers from registered user institutions then can be directed to these pages to identify the institutions and publications from and for which waivers are available, so they are not discouraged from submitting to their Open Access journal of choice.

\section{Conclusion}

Conscious efforts like these to develop the vibrancy and capability of the research community in Research4Life countries will pay dividends in the long term, ensuring that the growing cohort of scientists from LMICs are active participants in shaping the knowledge generation and transfer mechanisms that will underpin the achievement of the Sustainable Development Goals. Such efforts must be collaborative and collective in order to achieve maximum impact at scale. 


\section{Data Sources \& Methodology}

Using Scopus, publications with at least one author affiliated with a Research4Life country were identified. Publications were limited to those published between 2009 and 2018 and the document types that are typically peer reviewed: articles, reviews, conference proceedings, short surveys and data papers. Open Access status was captured using known journal business models with

\section{References}

Bifano, C. (2014, June 12). Capacity building: Architects of South American science. Nature, 510, 209-212. doi:10.1038/510209a

Clarivate Analytics. (2019). Navigating the Structure of Research on Sustainable Development Goals. Retrieved May 29, 2020, from https://clarivate.com/webofsciencegroup/campaigns/ sustainable-development-goals/

Information Power. (2020). Project to explore open access agreements between society publishers and library consortia in developing and transition economy countries. Retrieved May 29, 2020, from Information Power: https://www.informationpower. co.uk/project-to-explore-open-access-agreements-betweensociety-publishers-and-library-consortia-in-developing-andtransition-economy-countries/

Johnson, R., Watkinson, A., \& Mabe, M. (2018). The STM Report: An overview of scientific and scholarly publishing. Retrieved May 29, 2020, from https://www.stm-assoc.org/2018_10_04_STM _ Report_2018.pdf

Nobes, A., \& Harris, S. (2019). Open Access in low-and middleincome countries; attitudes and experiences of researchers. Emerald Open Research, 1(17). doi: doi.org/10.35241/ emeraldopenres.13325.1

Publons. (2018). 2018 Global State of Peer Review. Retrieved May 29, 2020, from https://publons.com/static/Publons-Global-StateOf-Peer-Review-2018.pdf

Purcell, W. M., Henriksen, H., \& Spengler, J. D. (2019). Universities as the engine of transformational sustainability
Unpaywall data, which identifies the Open Access model at the article level. Further, bioRxiv data was captured for 2017, and the affiliated country was identified for authors using a combination of affiliation information and email address domains. For the comparison to biology journal articles, we used the Scopus publication set, limited to only those in the biology subject area. toward delivering the sustainable development goals: "Living labs" for sustainability. International Journal of Sustainability in Higher Education, 20(8), 1343-1357.

Research4Life. (2013). Beyond the 2015 Horizon: Research4Life's Current Strategic Plan. Retrieved May 29, 2020, from https:// www.research4life.org/wp-content/uploads/promotions/ StrategyR4L2012.pdf

Research4Life. (2020). Eligibility for access to Research4Life. Retrieved May 29, 2020, from Research4Life.org: https://www. research4life.org/access/eligibility/

Shih, I. (2017, May 22). Young researchers preach open access, yet many don't practice. Retrieved May 29, 2020, from Nature Index: https://www.natureindex.com/news-blog/ young-researchers-preach-open-access-yet-many-dont-practice

Thanh Tien, H. (2016). Vietnamese academic's research capacity in tertiary contexts. Retrieved May 29, 2020, from https://pdfs. semanticscholar.org/7c47/f741e85b491fe2d 4880aag16c8geabd5eo5f.pdf

Warden, R. (2017, September 21). SDGs - Universities are moving from what to do to how. Retrieved May 29, 2020, from University World News: https://www.universityworldnews.com/post. php?story=20170921171919144

Wired. (2013, October 18). The secret behind Iraq's scientific resurgence. Retrieved May 29, 2020, from Wired: https://www. wired.com/2013/10/the-secret-behind-iraqs-scientific-resurgence/ 


\section{About the Authors}

\section{Andrea Powell}

Andrea Powell has acted as the Publisher Coordinator for Research4Life since November 2018. Prior to this, she spent 26 years with $\mathrm{CABI}$, where her most recent role was Chief Information Officer overseeing CABI's Knowledge Business and global IT operation. While at CABI Andrea served on the Council of ALPSP and on the Board of STM. Andrea is also an Associate Lecturer at Oxford Brookes University and a Non-Executive Director for the Pharmaceutical Press.

\section{Rob Johnson}

Rob Johnson is the founder and director of Research Consulting, a mission-driven business which works to improve the effectiveness and impact of research and scholarly communication. Rob began his career with KPMG, the international professional services firm, and spent four years as Head of Research Operations at the University of Nottingham. Since founding Research Consulting in early 2013 he has led more than 50 studies on the transition to open access and open research data, acting as an independent, trusted advisor for research funders, academic institutions, publishers and learned societies in the UK, Europe and worldwide.

\section{Rachel Herbert}

Rachel Herbert is a Senior Research Evaluation Manager at Elsevier. She has worked in scholarly publishing for over 10 years and has an active interest in the evaluation of research, particularly through the lens of gender. Her work focuses on developing analytical approaches to derive insights about the world of research using bibliometric and scientometric tools.

\section{How to cite:}

Powell A., Johnson R., \& Herbert R. (2020). Achieving an Equitable Transition to Open Access for Researchers in Lower and Middle-Income Countries. ICSR Perspectives https://dx.doi.org/10.2139/ssrn.3624782

\section{About the STM Association}

At STM we support our members in their mission to advance research worldwide. Our over 140 members based in over 20 countries around the world collectively publish $66 \%$ of all journal articles and tens of thousands of monographs and reference works. As academic and professional publishers, learned societies, university presses, start-ups and established players we work together to serve society by developing standards and technology to ensure research is of high quality, trustworthy and easy to access. We promote the contribution that publishers make to innovation, openness and the sharing of knowledge and embrace change to support the growth and sustainability of the research ecosystem. As a common good, we provide data and analysis for all involved in the global activity of research.

\section{Learn more:}

www.stm-assoc.org

@STMAssoc

@R4LPartnership

\section{About the International Center for the Study of Research}

The mission of the International Center for the Study of Research (ICSR) is to further the study of research and thus to contribute to the evidence base supporting the practice of research strategy, evaluation and policy. Our vision is a world in which decisions informed by such evidence benefit research and society.

ICSR delivers on this mission by identifying critical challenges and questions in research (organized around key research themes), which are developed with key stakeholders including funders, institutions (ICSR Partners), experts in the study of research and researchers themselves. We are also supported by an external ICSR Advisory Board.

Learn more and sign up for email alerts: www.elsevier.com/icsr

@IntCtrStudyRes 